\title{
Current problems of development of the journal of Computer Optics
}

\author{
D.V. Kudryashov ${ }^{1}$ \\ ${ }^{1}$ Samara National Research University, 34 Moskovskoe Shosse, 443086, Samara, Russia
}

\begin{abstract}
This paper presents overall results of two years experience in executing tasks defined in article "Quo Vadis" written by the Editor-in-Chief of the journal of Computer Optics, Corresponding Member of RAS V.A. Soifer (Computer Optics 2014; Volume 38, Issue 4). The main bibliometric indicators of the journal in SCOPUS citation database are compared with similar metrics of some most relevant periodicals. The paper declares some important events to be held in 2017. Based on the current progress of the journal, new objectives of its further development are defined, and major events targeted for 2017 are discussed.
\end{abstract}

Keywords: scientific journal; journal promotion; bibliometric indicators; SCOPUS; comparison of metrics; quartile; development plan

\section{Introduction}

The scientific journal of Computer Optics has been issued since 1987 in Russian and English languages. During this period totally 40 volumes were published, including over 1.500 scientific articles. From 2007, the journal was issued 4 times a year.

In the mid 2014s, the Editor-in-Chief of the journal, Corresponding Member of RAS V.A. Soifer in his article "Quo Vadis" [1] set new tasks for the authors and the editorial team, the majority of which required at least two years to be implemented. Execution of tasks defined in [1] allowed the journal to significantly improve its bibliometric indicators [2-3].

\section{Results of two years development}

In 2015, we published five issues of the journal in Russian and recommenced publishing its English version entitled Computer Optics Selected Papers (it included articles translated into English and published in previous issues of the journal of Computer Optics). From 2016, the journal has been published 6 times a year, plus one more issue of Computer Optics Selected Papers published additionally. This allows us to reduce deadlines for publication of peer-reviewed papers to two or three months.

The deadline for papers peer-reviewing was significantly reduced in the last two years. The number of reviewers was greatly expanded. Each paper is now evaluated at least by two experts [2], usually being Doctors of Sciences and working in different institutions of RAS and some leading Russian universities.

The Editorial Board of the journal of Computer Optics was also expanded and it now includes, along with leading scientists from Germany, India, China and Finland [4], also some famous scientists from the USA, Great Britain and Ireland.

According to international standards, the journal has been added with information on article citations. Each article has been supplied with its unique Digital Object Identifier (DOI). Requirements for submitting the References in English have been changed, and they are now drew up not according to GOST (Russian State Standard) requirements, but in accordance with requirements of the largest international citation database SCOPUS. In Computer Optics, the number of foreign sources in the References has been significantly increased too. This drastically raises the prospect of an article to be widely cited in other periodicals and thus a citation rate of Computer Optics to be improved [4]. In subsequent issues of the journal, expatriate members of the Editorial Board will focus on the number of citations in foreign sources given in the article. Beginning from 2009, archive materials of Computer Optics are added to SCOPUT database that has an impact on improving the citation rate of the journal [5]. We are currently working on adding its issues dated from 2005 to this database.

Changes have also taken place in the journal content - new publication categories have appeared: Earth's Remote Sensing Technology, including development of hyperspectral equipment [6-9]; photonic-crystal sensors [10-11]; LED technology [1213]; video signal stream processing and some other new methods of image subject processing [14-18]; new types of laser beams [19-20]; and academic reviews of up-to-date trends have been published [21-22]. In 2016, for the first time in a long period, a full-text English version of the journal of Computer Optics was issued with the articles originally written in English (Volume 40, Issue 5), which had not previously been published elsewhere.

The journal of Computer Optics is an Open Access periodical: coordinated pdf-versions of its articles are available in open access on the journal website: www.computeroptics.smr.ru; moreover, their publication is free for the authors. We may also review or download the articles in Russian and foreign databases, repositories and e-libraries.

Since 2012, the journal already represented in the Russian Science Citation Index (RSCI) has been peer-reviewed and indexed in international scientific citation databases SCOPUS and Compendex that became impactful advances for the regional journal with no full-text version in English [5]. Within 2015, the journal began to be represented in CyberLeninka e-library, in MathNet, Applied Science \& Technology Source Ultimate (EBSCO Publishing), Inspec databases. At the end of 2015, the journal of Computer Optics was included into the Russian periodical scientometric database -Russian Science Citation Index (RSCI) - within the Web of Science network from Thomson Reuters. The journal RSCI records will allow us to improve its quality by conforming to international standard requirements and to increase its bibliometric indicators in Web of Science and 
total integral indicators of Russia due to increasing its accessibility and citation level worldwide [4]. The next step for the journal should be its entry to Web of Science Core Collection database. For this purpose, we will proceed to attract new highlevel scientific papers and to expand the authors range, thus providing actual opportunities for fast and open access publication.

\section{Facts and figures}

Measures taken by the Editor-in-Chief of the journal to fulfill its major objectives have resulted in significant improvement of key scientometric indicators of Computer Optics in the most influential Russian and foreign databases.

Upon its current indicators, the journal of Computer Optics has been almost equated with the Journal of Modern Optics and has exceeded some impactful and influential journals such as Optik (Jena), Optical Engineering and Technical Physics Journal. In accordance with SCImago Journal \& Country Rank indicators, the journal of Computer Optics has entered into the second quartile in all relevant subject domains. Its Hirsch index comes up to 10.

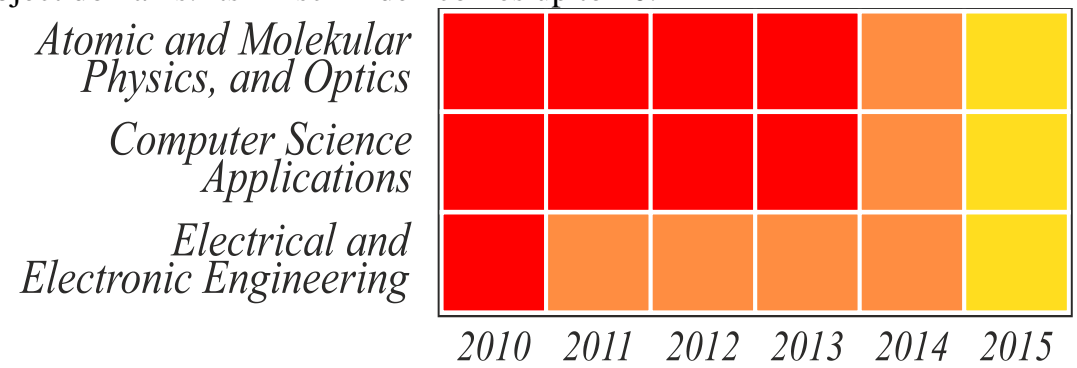

Fig. 1. The journal of Computer Optics entered into quartiles in three main areas: Physics and Optics; IT; Electronics (red - the $4^{\text {th }}$ quartile, fawn-colored the $3^{\text {rd }}$ quartile, yellow - the $2^{\text {nd }}$ quartile).

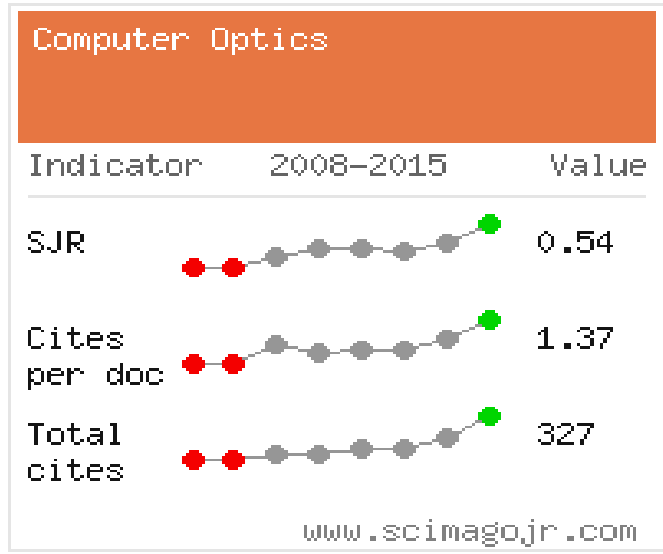

Fig. 2. Key scientometric indicators of the journal of Computer Optics according to SCImago Journal \& Country Rank.

Key scientometric indicators of the journal of Computer Optics in RSCI (data valid as of 2015):

- 2-Years Impact Factor - 1.182

- 5-Years Impact Factor- 0.902

- $\quad$ article citations in previous 2 years -506

- $\quad$ article citations in previous 5 tears -368

- the Herfindahl Index (last 5 years) according to citing journals - 1390

- the Herfindahl Index according to authors' institutions - 2470

- the H-Index (last 10 years) - 13

- total journal citations in RSCI - about 6000.

Key scientometric indicators of the journal of Computer Optics in SCOPUS database (data valid as of 2015):

SJR indicator (SCImago Journal Rank) - 0.535

IPP (Impact per Publication) - 1.185

SNIP (Source Normalized Impact per Paper) - 1.284

CiteScore metrics (citations in 2015 Scopus database published in 2012 through 2014 divided by the number of the articles): 1.22 (in $2016-1.59$ ).

Table 1. Change in the article citation level in Computer Optics (according to SCOPUS database)

\begin{tabular}{|lll|}
\hline Year & Number of articles & Number of citations \\
\hline 2009 & 41 & 11 \\
\hline 2010 & 64 & 40 \\
\hline 2011 & 70 & 48 \\
\hline 2012 & 80 & 84 \\
\hline 2013 & 68 & 104 \\
\hline 2014 & 124 & 260 \\
\hline 2015 & 106 & 452 \\
\hline
\end{tabular}


Key indicators of Computer Optics according to SCOPUS database compared with the most relevant publications are given in details in Figures 3-5.

Table 2. Key scientometric indicators of the journal of Computer Optics as compared to the most relevant journals (according to SCOPUS as of 2015)

\begin{tabular}{|lllll|}
\hline No. & Title & CiteScore & SNIP & SJR \\
\hline 1 & Optics Express & 3.78 & 1.664 & 2.186 \\
\hline 2 & Applied Optics & 1.66 & 1.147 & 0.898 \\
\hline 3 & Journal of Optics & 1.44 & 0.631 & 0.765 \\
\hline 4 & Computer Optics & 1.22 & 1.284 & 0.535 \\
\hline 5 & Quantum Electronics & 1.07 & 1.124 & 0.631 \\
\hline 6 & $\begin{array}{l}\text { Optical Memory and Neural Networks } \\
\text { (Information Optics) }\end{array}$ & 0.76 & 1.372 & 0.344 \\
\hline & & & & \\
\hline
\end{tabular}

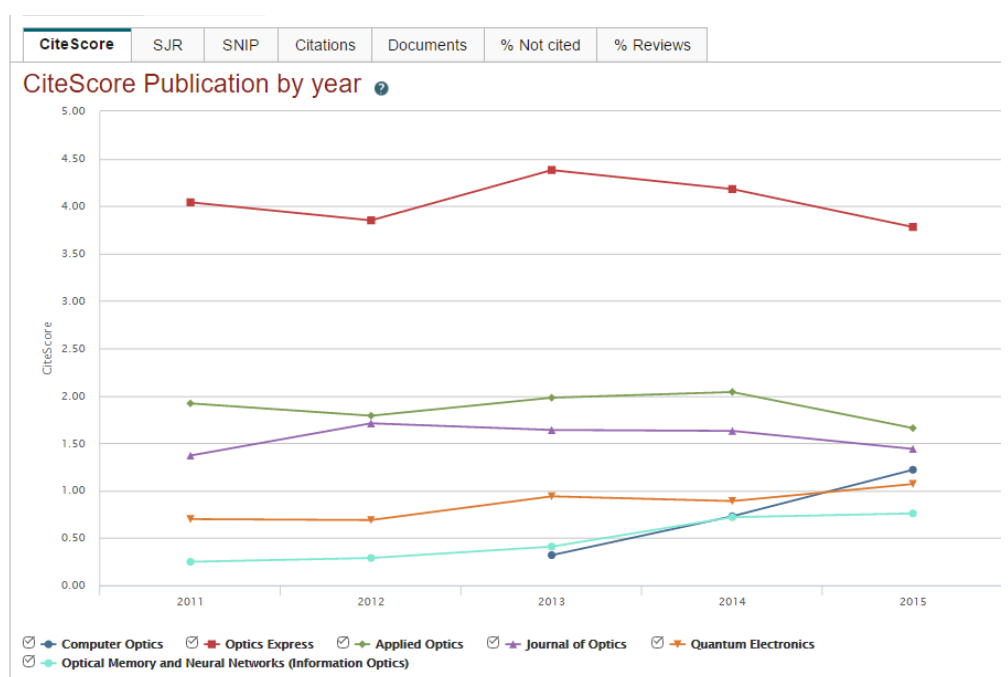

Fig. 3. CiteScore ranking of the journal of Computer Optics as compared to the most relevant journals.

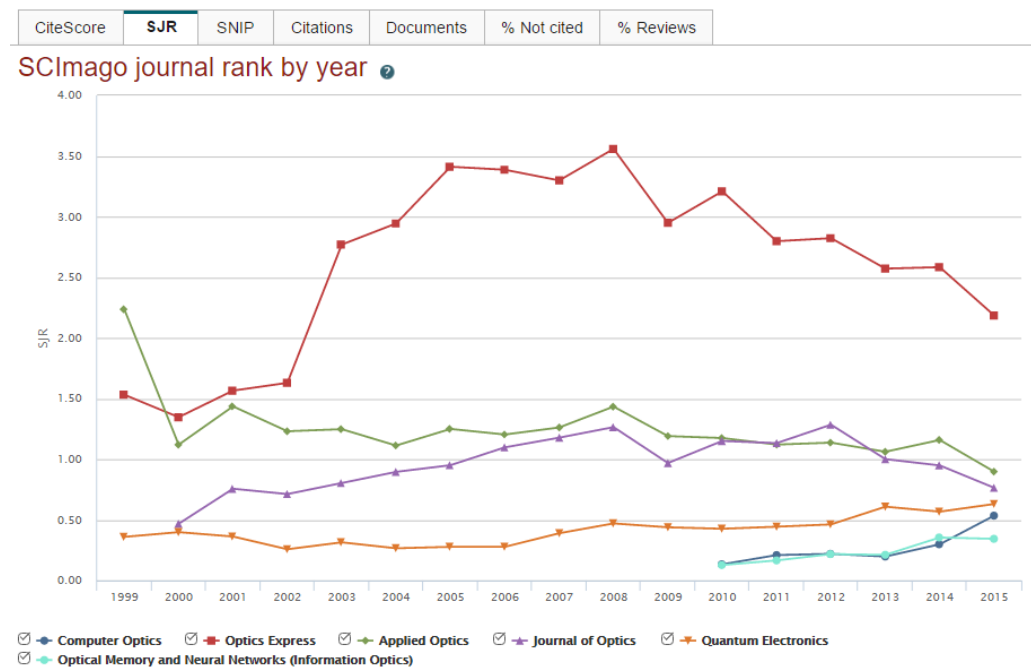

Fig. 4. SJR ranking of the journal of Computer Optics as compared to the most relevant journals.

\section{Conclusion}

The goal of the present stage of development of the journal is its entry into the Web of Science Core Collection. For this purpose, the Editorial Board intends to continue its work in several ways:

- improvement of publications quality,

- preparation of various reviews on relevant topics,

- $\quad$ strict conformance to peer-reviewing and issuing deadlines.

In 2017, we plan to prepare the third issue of Selected Papers (English versions of the articles published in the journal in 2015-2016) and a fully English-translated issue (Issue 4, 2017), and to expand a list of reference databases wherein the journal is represented. 


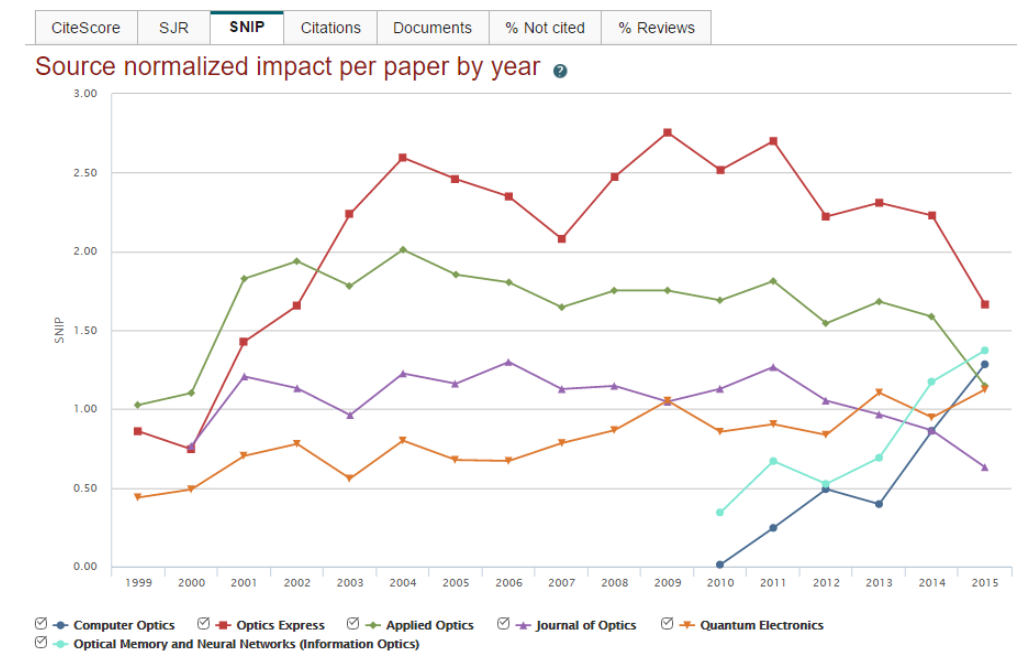

Fig. 5. SNIP ranking of the journal of Computer Optics as compared to the most relevant journals.

\section{Acknowledgements}

The author is deeply indebted to A.A. Bukhanko, Dr. Sci. in Physics and Mathematics, N.L. Kazanskiy, Dr. Sci. in Physics and Mathematics, A.V. Kupriyanov, Dr. Sci. in Physics and Mathematics, and S.S. Stafeev, Cand. Sci. in Physics and Mathematics, for their help and useful discussions.

\section{References}

[1] Soifer VA. Quo vadis. Computer Optics 2014; 38(4): 589.

[2] Kazanskiy NL. Advances of the journal of Computer Optics. Computer Optics 2017; 41(1): 139-141. (in Russian) DOI: 10.18287/2412-6179-2017-41-1139-141.

[3] Sokolov VO. Contribution of Samara scientists into Computer Optics journal development. CEUR Workshop Proceedings 2016; 1638: 194-206. DOI: 10.18287/1613-0073-2016-1638-194-206.

[4] Kolomiets EI. Analysis of activity of the scientific journal Computer Optics. Proceedings of Information Technology and Nanotechnology (ITNT-2015). CEUR Workshop Proceedings 2015; 1490: 138-150. DOI: 10.18287/1613-0073-2015-1490-138-150.

[5] Kudryashov DV. The scientific advancement and promotion of the journal "Computer Optics" in 2014-2015. CEUR Workshop Proceedings, 2016; 1638: 185-193. DOI: 10.18287/1613-0073-2016-1638-185-193.

[6] Kazankiy NL, Kharitonov SI, Khonina SN. Simulation of a hyperspectrometer based on linear spectral filters using vector Bessel beams. Computer Optics 2014; 38(4): 770-776. (in Russian)

[7] Golovin AD, Demin AV. Simulation model of a multichannel Offner hyperspectrometer. Computer Optics 2015; 39(4): 521-528. DOI: 10.18287/01342452-2015-39-4-521-528.

[8] Kazanskiy NL, Kharitonov SI, Doskolovich LL, Pavelev AV. Modeling the performance of a spaceborne hyperspectrometer based on the Offner scheme. Computer Optics 2015; 39(1): 70-76. DOI: 10.18287/0134-2452-2015-39-1-70-76.

[9] Karpeev SV, Khonina SN, Kharitonov SI. Study of the Diffraction Grating on a Convex Surface as a Dispersive Element. Computer Optics 2015; 39(2): 211-217. DOI: 10.18287/0134-2452-2015-39-2-211-217.

[10] Egorov AV, Kazanskiy NL, Serafimovich PG. Using Coupled Photonic Crystal Cavities for Increasing of Sensor Sensitivity. Computer Optics 2015; 39(2): 158-162. DOI: 10.18287/0134-2452-2015-39-2-158-162.

[11] Kadomina EA, Bezus EA, Doskolovich LL. Resonant photonic-crystal structures with a diffraction grating for refractive index sensing. Computer Optics 2016; 40(2): 164-172. DOI: 10.18287/2412-6179-2016-40-2-164-172.

[12] Kazanskiy NL, Stepanenko IS, Khaimovich AI, Kravchenko SV, Byzov EV, Moiseev MA. Injectional multilens molding parameters optimization. Computer Optics 2016; 40(2): 203-214. DOI: 10.18287/2412-6179-2016-40-2-203-214.

[13] Doskolovich LL, Andreev ES, Byzov EV. Analytical design of mirrors generating prescribed two-dimensional intensity distributions. Computer Optics 2016; 40(3): 346-352. DOI: 10.18287/2412-617-2016-40-3-346-352.

[14] Kazanskiy NL, Protsenko VI, Serafimovich PG. Comparison of system performance for streaming data analysis in image processing tasks by sliding window. Computer Optics 2014; 38(4): 804-810.

[15] Ilyasova NY, Kupriyanov AV, Paringer RA. Formation of features for improving the quality of medical diagnosis based on discriminant analysis methods Computer Optics 2014; 38(4): 851-855.

[16] Kotov AP, Fursov VA, Goshin YV. Technology for fast 3D-scene reconstruction from stereo images. Computer Optics 2015; 39(4): 600-605. DOI: 10.18287/0134-2452-2015-39-4-600-605.

[17] Boori MS, Kuznetsov AV, Choudhary KK, Kupriyanov AV. Satellite image analysis to evaluate the urban growth and land use changes in the city of Samara from 1975 to 2015. Computer Optics 2015; 39(5): 818-822. DOI: 10.18287/0134-2452-2015-39-5-818-822.

[18] Protsenko VI, Kazanskiy NL, Serafimovich PG. Real-time analysis of parameters of multiple object detection systems. Computer Optics 2015; 39(4): 582591. DOI: 10.18287/0134-2452-2015-39-4-582-591.

[19] Porfirev AP, Kovalev AA, Kotlyar VV. Optical trapping and moving of microparticles using asymmetrical Bessel-Gaussian beams. Computer Optics 2016; 40(2): 152-157. DOI: 10.18287/2412-6179-2016-40-2-152-157.

[20] Stafeev SS, Kotlyar MV, O’Faolain L, Nalimov AG, Kotlyar VV. A four-zone transmission azimuthal micropolarizer with phase shift. Computer Optics 2016; 40(1): 12-18. DOI: 10.18287/2412-6179-2016-40-1-12-18.

[21] Soifer VA, Korotkova O, Khonina SN, Shchepakina EA. Vortex beams in turbulent media: review. Computer Optics 2016; 40(5): 605-624. DOI: 10.18287/2412-6179-2016-40-5-605-624.

[22] Gashnikov MV, Glumov NI, Kuznetsov AV, Mitekin VA, Myasnikov VV, Sergeev VV. Image processing, pattern recognition: Hyperspectral remote sensing data compression and protection. Computer Optics 2016; 40(5): 689-712. DOI: 10.18287/2412-6179-2016-40-5-689-712. 